\title{
Color Tone of Various Melanoidins Produced from Model Systems
}

\author{
Hiroshi MotaI \\ Research Section, Kansai Factory, Kikkoman Shoyu Co., Ltd., \\ Takasago, Hyogo-ken, Japan
}

Received January 23, 1973

\begin{abstract}
The color tone of melanoidins prepared from model systems by heating mixtures of 1 mmole amino acid or peptide and $1 \mathrm{mmole}$ sugar in aqueous solution was investigated using $J$ A (change of $\log$ absorbance per $100 \mathrm{~m} \mu$ ) as a parameter of color tone.

Amino acids and peptides were responsible for the color tone of melanoidins while sugar had no effect on the color tone. In addition, the color tone of melanoidin varied as the concentration ratio of amino acid to sugar changed. Melanoidins from tryptophanand proline-xylose systems exhibited the lightest color tone. Melanoidins from peptides generally exhibited dark tones compared with those from amino acids.

Using the distribution pattern of color components fractionated by DEAE-cellulose chromatography, melanoidins have been classed into 4 groups based on the percentage of P1 (non-adsorbed fraction on DEAE-cellulose): group 1, melanoidins containing $90 \sim 100 \%$ $\mathrm{P} 1$; group 2, 70 80\% P1; group 3, 30 50\% P1; group 4, less than $20 \% \mathrm{P} 1$. Melanoidins derived from most amino acids examined, those from basic amino acids and proline, those from glutamic acid and glycine, and those from peptides and amino terminal monocarboxylic acids belonged to groups $2,1,3$, and 4 , respectively.

The color tone of each color component except for P1 was generally very similar in most melanoidins. However, the color tone of P1 was variable. Therefore, melanoidin is composed of various color components having intrinsic color tones from yellowish-brown to dark brown and their color tone depends upon the variation of the amount of color components and upon the color tone of P1.
\end{abstract}

Non-enzymatic browning by the Maillard reaction between carbonyl and amino groups is known as typical browning in various foods. Furthermore, it can be an indicator for many types of deteriorative changes in foods. Although the mechanism of browning and degree of browning in model system under various conditions have been intensively investigated, little is known about the color tone of melanoidins and the color tone of foods formed by the Maillard reaction, which is closely related to food quality.

In the previous paper, ${ }^{11}$ it was proposed that the change of $\log$ absorbance per $100 \mathrm{~m} \mu$ (designated as $\Delta \mathrm{A}$ ) could be used as a parameter of color tone, since a linear relationship between the above change and wavelength $(450 \sim 650 \mathrm{~m} \mu)$ was observed in the color of shoyu (soy sauce) and of melanoidins prepared using model systems.

To clarify the browning mechanism and properties of the browning material, the color tone of melanoidins prepared with model systems and the distribution of color components of melanoidins fractionated with DEAEcellulose have been investigated using $\triangle \mathrm{A}$ as a parameter of color tone.

\section{MATERIALS AND METHODS}

Chemicals. Amino acids and sugars were purchased from WAKO Pure Chemical Industries Ltd. and peptides were obtained from the Protein Research Foundation, Osaka, Japan. These chemicals were commercially available guaranteed reagents.

Model system. The model system contained 1 mmole amino acids or peptides and 1 mmole sugars in $5 \mathrm{ml}$ of $0.2 \mathrm{M}$ acetate buffer, $\mathrm{pH} 5.0$. The mixtures in glass tubes were frozen in acetonedry ice. The tubes were sealed under vacuum to prevent the oxidation of melanoidins as far as possible and were heated at $120^{\circ} \mathrm{C}$ for $60 \mathrm{~min}$, followed by immediate cooling in water. The seals of the tubes were broken and the samples were taken for measurements of absorbance 
and fractionation of the color components.

Estimation of $\triangle A$ as a parameter of color tone. The absorbance of melanoidins was measured at every $25 \mathrm{~m} \mu$ between 450 and $650 \mathrm{~m} \mu$. Then $\Delta \mathrm{A}$ was determined by plotting log absorbance against wavelength. The larger the value of $\Delta \mathrm{A}$, the brighter the color tone and the smaller $\Delta \mathrm{A}$, the darker the color tone.

Fractionation of color components. The above reaction mixtures containing browning materials formed by heating were diluted 20 -fold with distilled water, and then subjected to chromatography on DEAE-cellulose equilibrated with $0.01 \mathrm{M}$ acetate buffer, pH 5.0 (column size; $1 \times 20 \mathrm{~cm}$, flow rate; $100 \mathrm{ml} / \mathrm{hr}$ ). Stepwise elution was performed with the buffer, and with $0.025,0.05,0.10,0.15,0.20,0.30$ and $0.40 \mathrm{M} \mathrm{NaCl}$ in the same buffer. These color component fractions were disignated as P1, P2, P3, P4, P5, P6, P7, and P8 in order of elution, respectively. Each component was a single peak on DEAE-cellulose chromatography by gradient elution.

Estimation of amount of browning. The amount of browning was estimated from the absorbance at $450 \mathrm{~m} \mu$. The relative amount of browning is indicated as a percentage against total absorbance at $450 \mathrm{~m} \mu$ of melanoidin applied to the DEAE-cellulose.

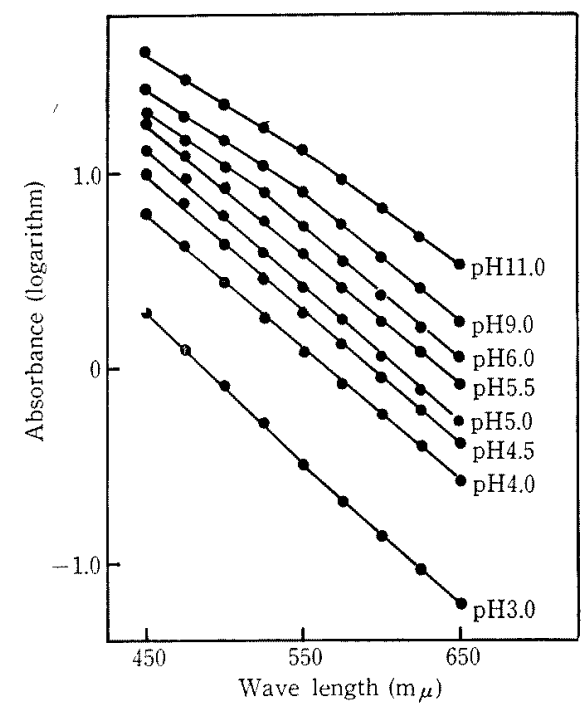

FIG. 1. Effect of $\mathrm{pH}$ on the Color Development of Melanoidins.

Melanoidins were prepared by heating a mixture of $1 \mathrm{mmole}$ glycine and $1 \mathrm{mmole}$ xylose in $5 \mathrm{ml}$ of $0.06 \mathrm{M}$ sodium citrate solution at $120^{\circ} \mathrm{C}$ for $60 \mathrm{~min}$ in a tube sealed under vacuum. The $\mathrm{pH}$ of the solution was adjusted with $1 \mathrm{~N} \mathrm{NaOH}$ and $1 \mathrm{~N} \mathrm{HCl}$.

\section{RESULTS AND DISCUSSION}

\section{Effect of $\mathrm{pH}$ on the color of melanoidin}

A linear relationship between log absorbance and wavelength was observed at $\mathrm{pH} 4.0$ to 5.5 (Fig. 1). These $\mathrm{pH}$ values represent limits which might naturally occur in various foods. The color tone of melanoidins was unchanged at $\mathrm{pH} 4.0$ to 5.5. Above $\mathrm{pH} 6.0$ and below $\mathrm{pH} 3.0$, the linear relationship between $\log$ absorbance and wavelength was lost in the vicinity of $550 \mathrm{~m} \mu$. More browning was found at higher $\mathrm{pH}$ values of the reaction mixture.

\section{Effect of amino groups on the color tone of melanoidins}

The amount of browning and the color tone of melanoidins formed by heating mixtures of amino acids or peptides and xylose is recorded in Fig. 2. The amount of browning

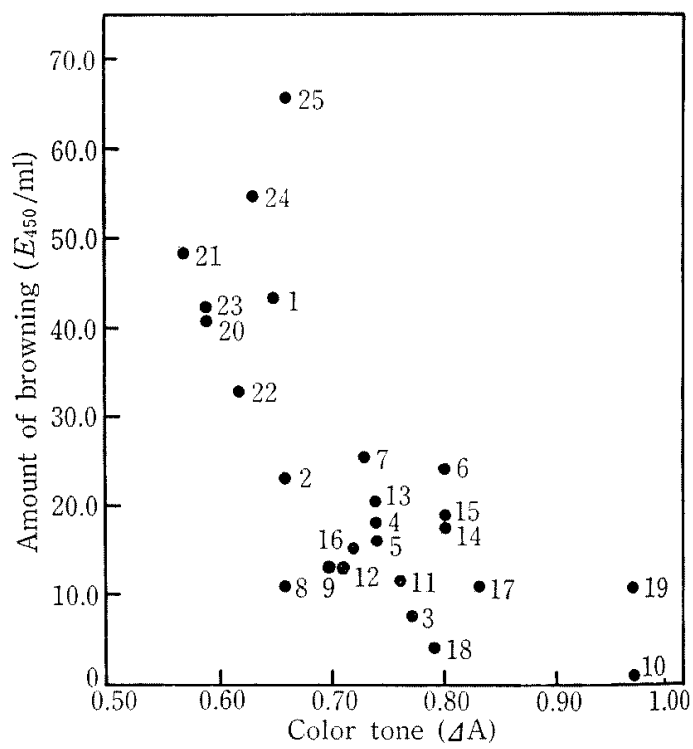

FIG. 2. Color of Melanoidins Formed in Model Systems.

1: Lys, 2: His, 3: Ala, 4: Thr, 5: Gly, 6: Asp, 7: Glu, 8: Gln, 9: Asn, 10: Pro, 11: Arg, 12: Ser, 13: Val, 14: Leu, 15: Ile, 16: Met, 17: Phe, 18: Tyr, 19: Trp, 20: Gly, 21: Gly-Leu, 22: Gly, 23: Gly-Phe, 24: Leu-Gly, 25 : Leu-Gly.

Melanoidins were prepared by heating a mixture of $1 \mathrm{mmole}$ amino acids or peptides and $1 \mathrm{mmole} x y l o s e$ in $5 \mathrm{ml}$ of $0.2 \mathrm{M}$ acetate buffer $\left(\mathrm{pH} 5.0\right.$ ) at $120^{\circ} \mathrm{C}$ for $60 \mathrm{~min}$ in a tube sealed under vacuum. 
and the color tone of melanoidins varied widely depending on the type of amino compound used. In general, peptides caused a significant increase in the amount of browning compared to amino acids. Amino acids such as Lys, His, Glu, and Asp resulted in the largest increase in the amount of browning of all amino acids tested.

On the other hand, the color tone of melanoidins from peptides generally was dark and those from Pro and Tyr exhibited the lightest tone of all the amino acids tested. Color tone of melanoidins from amides such as Gln and Asn and basic amino acids such as His and Lys exhibited a dark tone compared to those from other amino acids.

As shown in Fig. 3, which illustrates the distribution patterns of color components fractionated by DEAE-cellulose chromatography, melanoidins were grouped into 4 groups based on the content of Pl: group 1, melanoidins containing $90 \sim 100 \% \mathrm{P} 1$, group $2,70 \sim 80 \% \mathrm{P} 1$, group $3,30 \sim 50 \% \mathrm{Pl}$; group 4 , less than $20 \% \mathrm{P} 1$. Melanoidins from basic amino acids and Pro belong to group 1. Melanoidins from most amino acids and amides belong to group 2. Melanoidins from Gly and Glu belong to group 3. Melanoidins from peptides belong to group 4 .
As shown in Table I, $\Delta \mathrm{A}$ values of each color component of melanoidins derived from most amino compounds were similar. However, P1 from His and Lys showed somewhat lower $\Delta \mathrm{A}$, and $\mathrm{Pl}$ from Pro gave a somewhat higher $\Delta \mathrm{A}$ than those from other amino compounds. Therefore, the dark tone of melanoidins from Lys and His can be explained by the low $\Delta \mathrm{A}$ value of $\mathrm{Pl}$, which is the major component. Similarly, the light tone of melanoidins from Pro and Trp is due to the high $\triangle \mathrm{A}$ value of each color component.

A linear relationship between the $\log$ absorbance and wave length was not found in the color components P1 and P2 from Tyr, Trp, Leu-Gly and Leu-Gly.

Effect of sugars on the color tone of melanoidins

Amount of borwning and color tone of melanoidin from individual sugar-glycine systems are shown in Table II. The browning intensity of melanoidins was in the following order: Ribose $>$ Xylose $>$ Arabinose Mannose $>$ Eructose $>$ Glucose. With lactose, maltose and saccharose, browning did not occur. The color tones of melanoidins formed by heating a solution of glycine with various sugars were almost the same and each color component showed a similar $\Delta \mathrm{A}$ value. How -

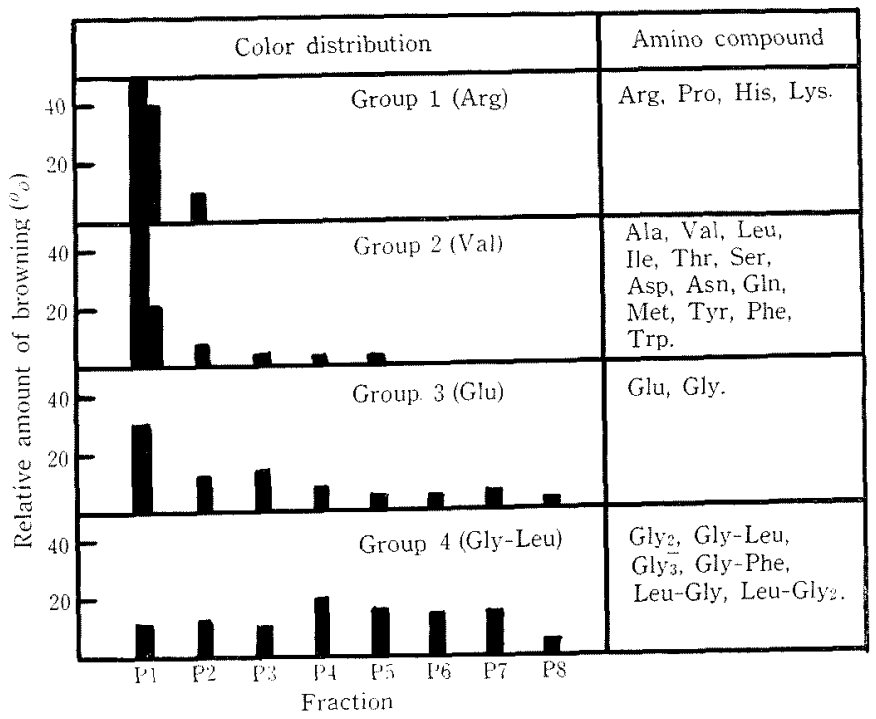

FIG. 3. Grouping of Melanoidins Based on Content of P1 Component. 
Table I. The Color Tone of Color Components of Various Melanoidins Derived from Different Amino Acids and Peptides

\begin{tabular}{|c|c|c|c|c|c|c|c|c|c|}
\hline \multirow{2}{*}{ Group } & \multirow{2}{*}{$\begin{array}{l}\text { Amino acid } \\
\text { or peptide }\end{array}$} & \multicolumn{8}{|c|}{$\Delta \mathrm{A}$} \\
\hline & & P1 & P2 & P3 & P4 & P5 & P6 & P7 & P8 \\
\hline \multirow{4}{*}{1} & Arg & 0.77 & 0.66 & - & - & - & - & - & - \\
\hline & $\mathrm{His}$ & 0.66 & - & - & - & - & - & - & - \\
\hline & Lys & 0.65 & 0.58 & - & - & - & - & - & - \\
\hline & Pro & 0.97 & - & - & - & - & - & - & - \\
\hline \multirow{13}{*}{2} & Ala & 0.78 & 0.65 & 0.57 & 0.55 & 0.48 & 0.45 & - & - \\
\hline & Val & 0.76 & 0.63 & 0.58 & 0.56 & 0.48 & 0.45 & 一 & - \\
\hline & Leu & 0.75 & 0.62 & 0.57 & 0.55 & - & - & - & - \\
\hline & Ile & 0.79 & 0.65 & 0.57 & 0.53 & 0.47 & 0.44 & 0.40 & - \\
\hline & Thr & 0.76 & 0.63 & 0.58 & 0.54 & - & - & - & - \\
\hline & Ser & 0.72 & 0.61 & 0.55 & 0.51 & 0.48 & 0.41 & 0.36 & - \\
\hline & Asp & 0.80 & 0.68 & 0.58 & 0.54 & - & - & - & - \\
\hline & Asn & 0.72 & 0.63 & 0.60 & 0.56 & 0.49 & 0.43 & 0.39 & - \\
\hline & Gln & 0.68 & 0.64 & 0.56 & 0.52 & 0.48 & 0.44 & 0.38 & - \\
\hline & Met & 0.79 & 0.68 & 0.60 & 0.54 & 0.47 & 0.45 & - & - \\
\hline & Tyr & N.E & N.E & 0.58 & 0.55 & 0.45 & 0.43 & - & - \\
\hline & Phe & 0.84 & 0.60 & 0.54 & 0.48 & 0.43 & 0.35 & - & - \\
\hline & Trp & N.E. & N.E. & 0.75 & 0.66 & 0.62 & 0.55 & - & - \\
\hline \multirow[t]{2}{*}{3} & Glu & 0.75 & 0.66 & 0.62 & 0.60 & 0.54 & 0.51 & 0.47 & 0.41 \\
\hline & Gly & 0.80 & 0.66 & 0.60 & 0.55 & 0.50 & 0.46 & 0.44 & 0.40 \\
\hline \multirow{6}{*}{4} & Gly & 0.80 & 0.70 & 0.62 & 0.54 & 0.50 & 0.46 & 0.43 & 0.38 \\
\hline & Gly-Leu & 0.77 & 0.68 & 0.65 & 0.57 & 0.48 & 0.42 & 0.41 & 0.38 \\
\hline & Gly-Phe & 0.72 & 0.63 & 0.57 & 0.55 & 0.50 & 0.44 & 0.37 & 0.34 \\
\hline & Leu-Gly & N.E & N.E & 0.63 & 0.54 & 0.48 & 0.43 & 0.37 & 0.34 \\
\hline & Leu-Gly 2 & N.E & N.E & 0.66 & 0.55 & 0.47 & 0.45 & 0.40 & 0.34 \\
\hline & Gly $_{3}$ & 0.80 & 0.70 & 0.60 & 0.58 & 0.51 & 0.46 & 0.42 & 0.38 \\
\hline
\end{tabular}

N.E: JA could not be estimated, since a linear relationship was not observed between log absorbance and wavelength. - - not detectable.

Table II. Color Tone of Melanoidins from Various SUGAR-GLYCINE SYSTEMS

\begin{tabular}{|c|c|c|c|c|c|c|c|c|c|c|}
\hline \multirow{2}{*}{ Sugars } & \multirow{2}{*}{$\Delta \mathrm{A}$} & \multirow{2}{*}{$E_{450} / \mathrm{ml}$} & \multicolumn{8}{|c|}{$\Delta \mathrm{A}$} \\
\hline & & & P1 & P2 & P3 & P4 & P5 & P6 & P7 & P8 \\
\hline Ribose & 0.74 & 20.06 & 0.82 & 0.66 & 0.60 & 0.55 & 0.51 & 0.46 & 0.44 & 0.40 \\
\hline Xylose & 0.74 & 18.07 & 0.80 & 0.66 & 0.60 & 0.55 & 0.50 & 0.46 & 0.44 & 0.40 \\
\hline Arabinose & 0.75 & 11.91 & 0.81 & 0.67 & 0.60 & 0.54 & 0.50 & 0.45 & 0.43 & 0.40 \\
\hline Fructose & 0.77 & 2.88 & 0.77 & 0.69 & 0.59 & 0.56 & 0.52 & 0.45 & 0.44 & 0.40 \\
\hline Mannose & 0.76 & 4.57 & 0.76 & 0.66 & 0.60 & 0.55 & 0.49 & 0.44 & 0.42 & 0.40 \\
\hline Glucose & 0.75 & 2.85 & 0.79 & 0.65 & 0.58 & 0.55 & 0.50 & 0.45 & 0.44 & 0.39 \\
\hline
\end{tabular}

ever Pl from pentose gave a considerably higher $J$ A value than that from hexose. Figure 4 illustrates the color distribution of melanoidins with various sugars. Carbonyl compounds such as sugars seemed to have no effect on the color tone of melanoidins, since melanoidins from various sugars showed al- most the same color tone. On the other hand, the color tone of melanoidins formed in model systems varied remarkably depending on the nature of the amino acids or peptides. Therefore, it is apparent that the color tone of melanoidins is governed by amino compounds but not by carbonyl compounds. 
Table III. Effect of Concentration of Xylose and Glycine on the

Color Tone of Melanoidins

\begin{tabular}{|c|c|c|c|c|c|c|c|c|c|c|c|}
\hline \multicolumn{2}{|c|}{$\begin{array}{c}\text { Concentration } \\
\text { (mmole) }\end{array}$} & \multirow{2}{*}{$\Delta \mathrm{A}$} & \multirow{2}{*}{$E_{450} / \mathrm{ml}$} & \multicolumn{8}{|c|}{$\Delta \mathrm{A}$} \\
\hline Glycine & Xylose & & & $\mathrm{P} 1$ & $\mathbf{P} 2$ & P3 & P4 & P5 & P6 & P7 & P8 \\
\hline 4.0 & 1.0 & 0.73 & 35.76 & 0.76 & 0.66 & 0.60 & 0.56 & 0.50 & 0.46 & 0.42 & 0.40 \\
\hline 2.0 & 1.0 & 0.74 & 22.41 & 0.80 & 0.67 & 0.62 & 0.58 & 0.51 & 0.46 & 0.41 & 0.40 \\
\hline 1.0 & 1.0 & 0.74 & 16.48 & 0.80 & 0.66 & 0.60 & 0.55 & 0.50 & 0.46 & 0.44 & 0.40 \\
\hline 0.5 & 1.0 & 0.78 & 5.53 & 0.80 & 0.66 & 0.58 & 0.53 & 0.50 & 0.47 & 0.42 & 0.39 \\
\hline 0.1 & 1.0 & 0.81 & 0.65 & 0.82 & 0.66 & N.E. & N.E. & N.E. & N.E. & N.E. & N.E. \\
\hline 1.0 & 4.0 & 0.66 & 58.55 & 0.72 & 0.66 & 0.61 & 0.56 & 0.50 & 0.47 & 0.44 & 0.40 \\
\hline 1.0 & 2.0 & 0.69 & 34.88 & 0.72 & 0.67 & 0.62 & 0.57 & 0.51 & 0.47 & 0.45 & 0.40 \\
\hline 1.0 & 0.5 & 0.77 & 4.08 & 0.80 & 0.65 & 0.60 & 0.58 & 0.52 & 0.47 & 0.44 & 0.41 \\
\hline 1.0 & 0.1 & N.E. & 1.37 & N.E. & N.E. & N.E. & N.E. & N.E. & N.E. & N.E. & N.E. \\
\hline
\end{tabular}

N.E.: JA could not be estimated, since a linear relationship was not observed between log absorbance and wavelength.

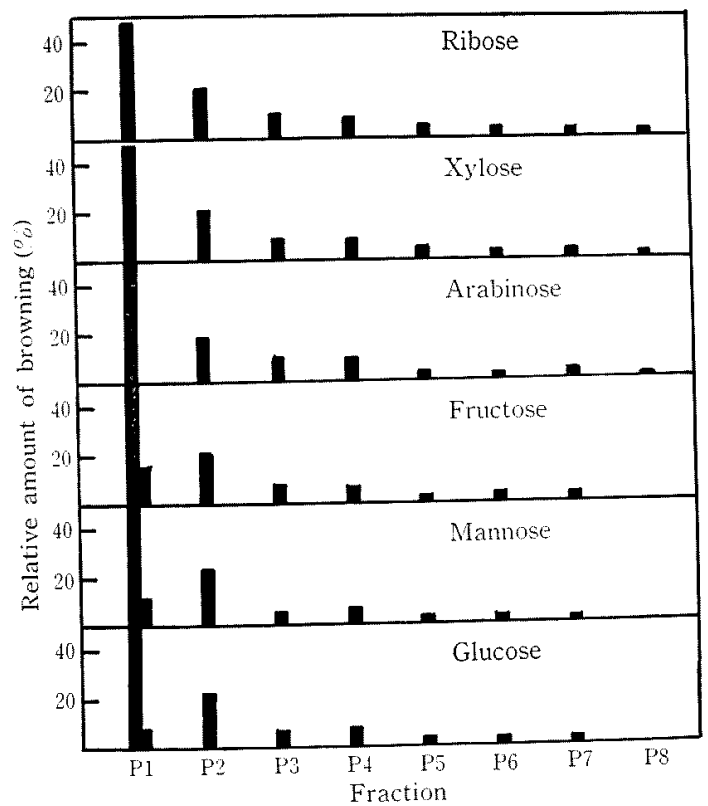

FIG. 4. Color Distribution of Melanoidins from Various Sugar-Glycine Systems.

Effect of concentration of xylose and glycine on the color tone of melanoidins

As seen in Table III, the color tone of melanoidins became lighter as the amount of sugar or amino acid became smaller. Each color component except $\mathrm{Pl}$ gave almost the same $\Delta \mathrm{A}$ but $\Delta \mathrm{A}$ for $\mathrm{P} 1$ was somewhat variable depending on the amounts of glycine and xylose.

Similarly, color components showing a light tone increased when the amounts of sugar

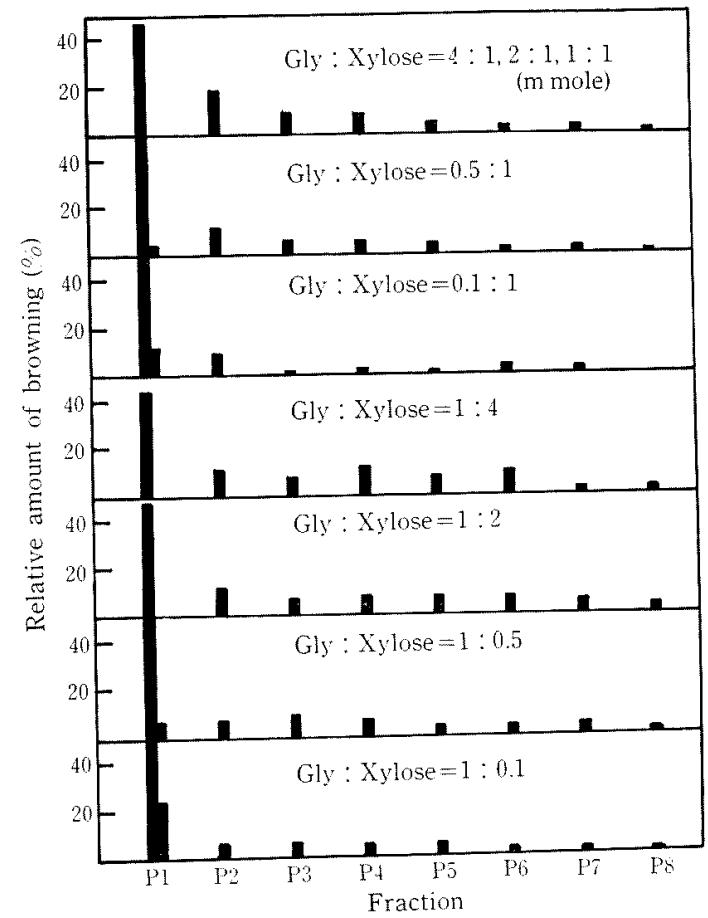

FIG. 5. Effect of Concentration of Xylose and Glycine on the Color Distribution of Melanoidins.

or amino acid decreased (Fig. 5).

Effect of position of the amino group in amino acid on the color tone of melanoidins

Table IV shows the effect of the position of the amino group of amino acids on the color tone of melanoidins with 3 different series of amino acids. The amount of browning on 
Table IV. Effect of the Position of the Amino Group in Amino Acids on the Color Tone of Melanoidins

\begin{tabular}{|c|c|c|c|c|c|c|c|c|c|c|}
\hline \multirow{2}{*}{ Amino acid } & \multirow{2}{*}{$\Delta \mathrm{A}$} & \multirow{2}{*}{$E_{460} / \mathrm{ml}$} & \multicolumn{8}{|c|}{$\Delta \mathrm{A}$} \\
\hline & & & P1 & P2 & P3 & P4 & P5 & P6 & P7 & P8 \\
\hline Glycine & 0.74 & 16.48 & 0.80 & 0.66 & 0.60 & 0.55 & 0.50 & 0.46 & 0.44 & 0.40 \\
\hline$\beta$-Alanine & 0.67 & 35.13 & 0.80 & 0.72 & 0.62 & 0.55 & 0.50 & 0.46 & 0.43 & 0.40 \\
\hline$\gamma$-Aminobutyric acid & 0.66 & 38.40 & 0.76 & 0.71 & 0.65 & 0.54 & 0.50 & 0.45 & 0.42 & 0.39 \\
\hline$\delta$-Aminovaleric acid & 0.66 & 30.33 & 0.82 & 0.70 & 0.60 & 0.53 & 0.48 & 0.44 & 0.41 & 0.39 \\
\hline$\Sigma$-Aminocaproic acid & 0.68 & 28.98 & 0.82 & 0.68 & 0.64 & 0.55 & 0.48 & 0.44 & 0.42 & 0.41 \\
\hline L-Alanine & 0.77 & 8.38 & 0.78 & 0.65 & 0.57 & 0.55 & 0.48 & 0.45 & 0.44 & 0.40 \\
\hline DL- $\alpha$-Aminobutyric acid & 0.76 & 12.10 & 0.81 & 0.65 & 0.59 & 0.52 & 0.47 & 0.43 & 0.43 & 0.40 \\
\hline DL-Norvaline & 0.80 & 12.60 & 0.82 & 0.65 & 0.59 & 0.54 & 0.51 & 0.44 & 0.42 & 0.39 \\
\hline DL-Norleucine & 0.83 & 11.60 & 0.86 & 0.67 & 0.58 & 0.52 & 0.48 & 0.45 & 0.44 & 0.40 \\
\hline DL-Diaminobutyric acid $-2 \mathrm{HCl}$ & 0.66 & 29.00 & 0.67 & 0.58 & - & - & - & - & - & -- \\
\hline DL-Ornithine-HCl & 0.64 & 33.40 & 0.65 & 0.56 & - & - & - & - & - & - \\
\hline L-Lysine & 0.65 & 42.78 & 0.65 & 0.56 & - & - & - & - & - & - \\
\hline
\end{tabular}

- : not detectable.

heating a mixture of xylose and each of these amino acids was almost the same as that found by Lento et al. ${ }^{2}$ with glucose and amino acids.

The color tone of melanoidins from aminoterminal monocarboxylic acids was darker than that from glycine. However, chain length (distance between amino group and carboxyl group) had no effect on the color tone of melanoidins. The color tone of melanoidins from monoamino acids with amino groups at the alpha position became lighter when the side-chain length of the molecule increased. Melanoidins from diamino acids showed a dark tone compared to those from other amino acids, but these gave a similar tone independent of chain length.

Color components of melanoidins except for P1 from monoamino acids with an amino group at the end of the chain and monoamino acids with an amino group in the alpha position showed similar $\Delta \mathrm{A}$ values. However P1 of melanoidins from monoamino acids with an amino group at the alpha position showed higher $\Delta \mathrm{A}$ with increasing side chain length. Melanoidins from diamino acids were composed of only P1 and P2. Each color component showed almost similar $\triangle \mathrm{A}$ values and low $\Delta \mathrm{A}$ values compared to those from other amino acids.

According to the grouping proposed with the data of Fig. 3, the distribution of color components of melanoidins from diamino acids belong to group 1, those from monoamino manocarboxylic acids belong to group 4, and those from monoamino acids with an amino group at the alpha position belong to group 2 (Fig. 6).

As regards the distribution pattern of color components, melanoidins could be classed into 4 groups based on the percentage of Pl. From the distribution pattern of the color component, the degree of stability to oxidation of each group may be estimated, since the color components of melanoidins formed in model systems were found to change on oxidation in the following way; $\mathrm{P} 1 \rightarrow \mathrm{P} 2 \rightarrow \mathrm{P} 3 \rightarrow$ $\mathrm{P} 4 \rightarrow \mathrm{P} 5 \rightarrow \mathrm{P} 6 \rightarrow \mathrm{P} 7 \rightarrow \mathrm{P}^{3} .^{3)} \quad$ Therefore, it is thought that the degree of stability to oxidation of melanoidins is in following order; group $1>$ group $2>$ group $3>$ group 4 . Actually, light color components in the melanoidins produced from peptides and terminal amino monocarboxylic acids were easily changed into dark color components.

$\mathrm{P} 1$ showed somewhat variable $\Delta \mathrm{A}$ values in most melanoidins. In general, P1 is unstable to oxidation compared to the other color components. On exposure to air, P1 is liable to become dark compared to the other color components. These facts may explain the variable $\Delta \mathrm{A}$ values of $\mathrm{P} 1$ component. 


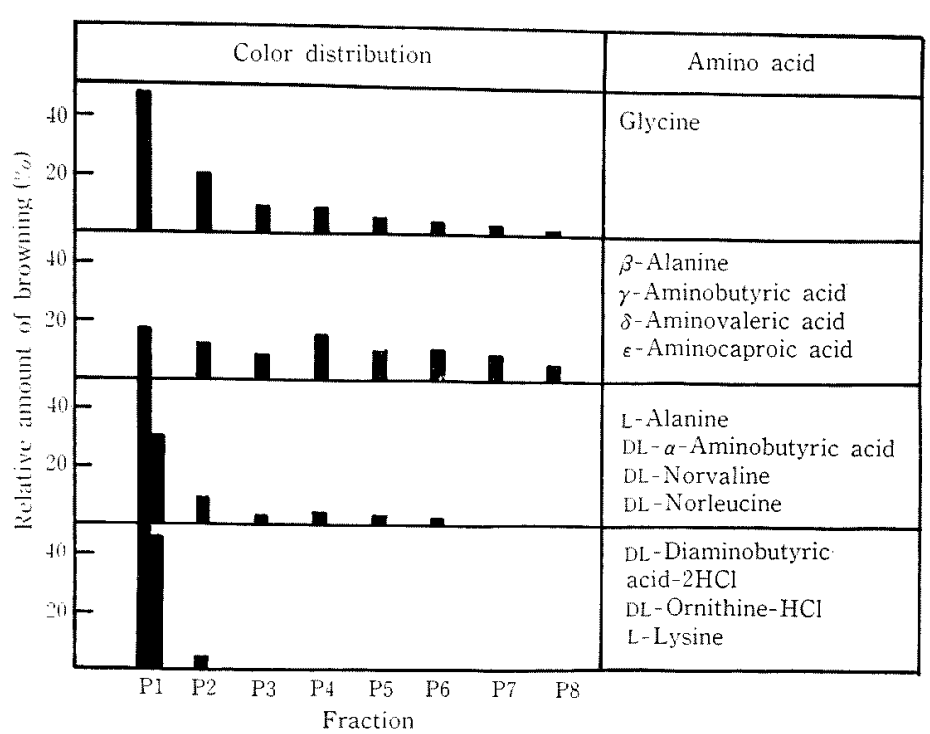

FIG. 6. Effect of the Position of the Amino Group in Amino Acids on the Color Distribution of Melanoidins.

In most melanoidins produced in the model systems, the color tone of each color component darkened according to the order of elution and each color component from $\mathrm{P} 2$ to $\mathrm{P} 8$ except for $\mathrm{P} 1$ gave similar $\triangle \mathrm{A}$ values. Therefore, the dark tone of melanoidins belonging to group 4 can be expalined by the presence of a large amount of color components showing dark tone and the light tone of melanoidins belonging to groups 2 and 3 can be explained by the large amount of color components showing light tone.

It is concluded that melanoidins are composed of various color components having intrinsic color tones from yellowishbrown to dark brown and that their color tone depends upon the amount of color components and upon the color tone of P1.

Acknowledgements. The author is greatly indebted to Prof. T. Kobayashi and Dr. S. Nasuno for their helpful suggestions and help in the preparation of this manuscript. The author also thanks Dr. T. Ueno and Mr. Y. Nishizawa for their encouragement and Miss M. Yamauchi for her skillful assistance.

\section{REFERENCES}

1) H. Motai, S. Inoue and Y. Nishizawa, Nippon Nogeikagaku Kaishi, 46, 631 (1972).

2) H. G. Lento, Jr., J. C. Underwood and C. O. Willits, Food Research, 23, 68 (1958).

3) H. Motai and S. Inoue, Abstract of Paper, Annual Meeting of Agricultural Chemical Society of Japan, Sendai, April, 1972, p. 222. 